\title{
SENTIDOS DA DOCÊNCIA EM ODONTOLOGIA: MEMORIAL
}

http://dx.doi.org/10.5902/2318133866663

\author{
Beatriz Unfer ${ }^{1}$
}

\begin{abstract}
Resumo
Este memorial atende os critérios estabelecidos para a promoção à Classe E - Titular - da Universidade Federal de Santa Maria. Constitui a análise de minha trajetória profissional e a oportunidade de dar visibilidade à minha forma de pensar e agir como docente nesta instituição. Atribuo significados e valores qualitativos sobre os valores quantitativos estabelecidos em relatórios, tabelas, gráficos e planilhas que acompanharam minhas atividades de ensino, pesquisa e extensão nestes 25 anos de vida acadêmica e, especialmente, nestes últimos dez anos. $O$ ano de 2017 tem um significado muito especial: um (re)começo.

Palavras-chave: ensino em Odontologia; sentidos; memorial.
\end{abstract}

\section{SENSES OF TEACHING IN DENTISTRY: MEMORIAL}

\begin{abstract}
This memorial meets the criteria established for the promotion to Class $\mathrm{E}$ - Holder - of the Federal University of Santa Maria. It constitutes the analysis of my professional trajectory and the opportunity to give visibility to my way of thinking and acting as a professor at this institution. I attribute qualitative meanings and values to the quantitative values established in reports, tables, graphs, and spreadsheets that accompanied my teaching, research, and extension activities in these 25 years of academic life and, especially, in these last ten years. The year 2017 has a special meaning: a (re)start.

Key-words: Dentistry teaching; senses; memorial.
\end{abstract}

1 Universidade Federal de Santa Maria, Brasil. E-mail: beatriz.unfer@ufsm.br. 


\section{Introdução}

exercício de análise de uma trajetória acadêmica, para a progressão à classe de professor titular, tem duas funções: a de historiar os procedimentos de trabalho que orientaram a prática docente, e a de nos fazer interpretar os momentos que se distinguiram do cotidiano, mas que não foram percebidos pela maioria das pessoas com quem convivemos no mundo do trabalho.

Situo três referências marcantes, entre outras, neste caminho rumo ao futuro profissional, que serão contextualizadas ao longo desta narrativa. A primeira delas foi quando disse ao meu pai que queria ser dentista: "Mas por que não queres ser professora?" A segunda foi da professora que me antecedeu na disciplina: "Tu não vais fazer mestrado em Odontopediatria! Vais fazer em Saúde Pública! Senão, esta disciplina vai desaparecer!' A terceira foi de uma colega do curso: "Por que não fazes um projeto de extensão e colocas em prática tuas ideias, para contemplar o que desejas para a disciplina?'

Ingressei na UFSM em 1985 como servidor técnico-administrativo concursado, na função de cirurgiã-dentista, na Coordenadoria de Planejamento Comunitário, órgão vinculado à Pró-Reitoria de Assuntos Estudantis. Durante seis anos trabalhei no serviço odontológico atendendo adultos e depois só crianças, já que havia me especializado em Odontopediatria.

Realizei concurso para a docência em 1991 e minha primeira opção era a disciplina de Odontopediatria, uma vez que possuía a especialidade e se constituía na minha prática profissional predominante. No entanto, candidatei-me à vaga na então disciplina de Odontologia Social, a qual ministrava conteúdos e práticas voltadas aos escolares do ensino básico. E me tornei uma professora.

\section{Na graduação}

Em 1982, por meio da resolução n. 04, do Conselho Federal de Odontologia, foram estabelecidos os conteúdos e a duração, mínimos, dos cursos de Odontologia. Destacase nessa resolução a especificação da Odontologia Social como disciplina responsável pelos conteúdos preventivos sociais, deontológicos, legais e os de orientação profissional, e a inclusão de disciplinas da área de Ciências Sociais. Além disso, deveriam ser ministrados conhecimentos de planejamento e administração de serviços de saúde comunitária, trabalho em equipe de saúde, metodologia científica, pessoal auxiliar, bem como técnicas e equipamentos odontológicos simplificados. Era prevista também a implantação de atividades extramuros, como estágios supervisionados, preferencialmente em sistemas públicos de saúde (Brasil, 1982).

Até 1993 as disciplinas de Odontologia Social I e II, ofertadas no $6^{\circ}$ e $7^{\circ}$ semestres na UFSM, eram de responsabilidade de cinco professores - um com mestrado em Odontologia Social, um com especialização em Periodontia, um com mestrado em Odontopediatria, um em cargo administrativo e eu, com especialidade em Odontopediatria -, que atuavam predominantemente em programas de educação e prevenção em saúde bucal dirigidos a crianças e adolescentes das escolas do município. Os conteúdos eram predominantemente de odontologia preventiva, com abordagem mínima ou incipiente dos demais conteúdos previstos na resolução citada anteriormente. 
Em 1994, após uma reforma curricular, as disciplinas em que ministrei aulas passaram a se chamar Odontologia Preventiva e Social I, II e III, no $1^{\circ}, 2^{\circ}$ e $7^{\circ}$ semestres, com carga horária de 180 horas. Os conteúdos eram essencialmente os mesmos descritos anteriormente, com a diferença de que foi montada uma clínica odontológica, de sistema modular, numa escola estadual, para as atividades de prática clínica no $2^{\circ}$ e $7^{\circ}$ semestres, e dirigida especificamente ao atendimento odontológico dos escolares desta instituição. Em termos de conteúdos ministrados repetia-se a abordagem essencialmente de odontologia preventiva.

Em 1995 iniciei a pós-graduação na Universidade Estadual Júlio de Mesquita Filho/Araçatuba e um novo mundo se abriu, de conhecimentos e de possibilidades de trabalho docente. Minha dissertação de mestrado foi focada na análise sobre a conhecimentos e práticas de saúde bucal da população usuária do SUS e minha tese de doutorado analisou como foram formados, como pensavam e como agiam os cirurgiõesdentistas dos serviços públicos de saúde. Foram anos de estudo intenso, fundamentais para ter a indispensável compreensão da atuação de um professor de uma disciplina como a minha, entendida como formadora de um profissional de saúde bucal para atuar em todos os níveis de atenção em saúde e no atendimento das necessidades de saúde da população em geral, mas também com competências e habilidades para o trabalho no SUS. Por que no SUS?

O Sistema Único de Saúde, criado pela Constituição de 1988, foi regulamentado pela lei n. 8.080, denominada Lei Orgânica da Saúde. No art. 6ำ consta que a ordenação da formação de recursos humanos na área de saúde está incluída no campo de atuação do SUS. O art. 27 destaca como um dos objetivos da política de recursos humanos na área da saúde "a organização de um sistema de formação de recursos humanos em todos os níveis de ensino, inclusive de pós-graduação" e, em parágrafo único, indica que os serviços do SUS constituem campo de prática para o ensino e a pesquisa, com normatização conjunta com o sistema educacional (Brasil, 1990). Esta conjuntura advertia que a formação do cirurgião-dentista deveria ser reformulada.

Voltei em 2001 para a UFSM com muita energia para as mudanças que se faziam necessárias, tanto no currículo como, principalmente, na minha disciplina. Mas o quadro docente da disciplina não mudou. A caracterização de uma disciplina voltada para crianças e adolescentes foi mantida, inclusive com o doutoramento de dois professores em Odontopediatria. Não havia aspiração, comprometimento e capacidade necessárias para mudanças.

Em 2002 o Conselho Nacional de Educação instituiu as diretrizes curriculares nacionais do curso de graduação em Odontologia. A resolução CNE/CES n. 03/2002 (Brasil, 2002) veio para definir as competências e habilidades gerais e específicas requeridas para a formação do cirurgião-dentista. Pelo parágrafo único do art. 5ำ define-se que "a formação do cirurgião dentista deverá contemplar o sistema de saúde vigente no país, a atenção integral da saúde num sistema regionalizado e hierarquizado de referência e contrarreferência e o trabalho em equipe", mostrando claramente a inserção da instituição formadora no SUS. 
Diante destas novas normativas, em 2002, o curso de Odontologia da UFSM constituiu uma comissão de reforma curricular e do projeto pedagógico do curso, com o objetivo de implantar as diretrizes nacionais, da qual fiz parte. Vislumbrei a oportunidade de definir o novo papel da disciplina nesta nova configuração para a formação do aluno.

Contribuí na tarefa de elaborar o projeto político-pedagógico do curso, principalmente onde havia necessidade de contemplar as especificidades relativas ao que preconizavam as diretrizes quanto a formação voltada ao sistema de saúde vigente. Sugeri a atualização da denominação da minha disciplina, para Odontologia em Saúde Coletiva I, II e III, com carga horária de 180 horas. Mas não houve possibilidade de mudar seu foco odontopediátrico e agora, de cariologia, pois os docentes envolvidos não tinham, não têm, competências e habilidades na área da Saúde Coletiva e não manifestaram interesse para incorporar outros e novos conhecimentos na sua prática docente.

A Odontologia Social foi concebida originalmente como uma integração de conteúdos preventivos e sociais, no sentido de formar um profissional com concepções preventivas e consciente de sua responsabilidade social. No entanto, esta denominação adquiriu uma conotação de Odontologia dirigida para as camadas populacionais mais pobres, portanto, precária e sem qualidade. E esta conotação acompanhou a disciplina, mesmo com sua mudança de nome. Em quase todos os cursos de Odontologia do país o conteúdo programático não tem a mesma importância, na visão da maioria dos docentes e estudantes, que as disciplinas denominadas clínicas, para a formação do cirurgiãodentista.

A evolução do conhecimento e a mudança do perfil da disciplina não foram - não são - suficientes para desencadear o reconhecimento de seu papel na formação do aluno. Minhas inquietações constantes eram: o mercado de trabalho cresce a cada ano no SUS, seja por dificuldades no mercado privado, seja por interesse do profissional numa fonte de renda fixa. Como podemos formar um cirurgião-dentista sem os conteúdos de Saúde Coletiva? Como fazer com que os futuros profissionais conheçam o SUS e acreditem nele? Como fazer com que este profissional atenda às necessidades da população usuária do sistema, com múltiplas doenças e agravos, e não somente cárie dentária? Como faço para ministrar os conteúdos de Saúde Coletiva, se não tenho disciplina, só o nome?

Estas e outras questões me fizeram acionar, informal e formalmente, o departamento administrativo, também denominado departamento didático, mas sem nenhum retorno. O que me fez constatar algo: do ponto de vista administrativo, característico na UFSM, temos departamentos focados na administração dos docentes carga horária, férias, produção institucional -, coordenações dos cursos focadas na administração dos alunos - matrículas, remanejamentos, formatura -, mas nenhuma instância administrativa focada na aprendizagem.

Assim, a disciplina foi descaracterizada como necessária ou importante no contexto da formação. E a Odontologia em Saúde Coletiva, como área de conhecimento e disciplina, encolheu, restrita a 30 horas teóricas e uma docente.

Durante mais de dez anos falei sozinha de Saúde Coletiva e de SUS no curso. Optei por me desligar das duas disciplinas clínico-odontopediátricas II e III e concentrar esforços na disciplina de Odontologia em Saúde Coletiva I no primeiro semestre do curso com os conteúdos possíveis de serem ministrados em apenas 30 horas semestrais. Era o único 
momento da formação em que o aluno tinha oportunidade de saber como funciona o sistema e desmistificar ou desconstruir toda a desinformação que recebe da mídia ou de outras pessoas, inclusive professores. Prova disto é o depoimento dos alunos por ocasião dos seminários finais, quando eles retornam das visitas que realizam em vários serviços do SUS: "Eu não sabia que o SUS era assim"; "Eu pensava que era precário e com profissionais desqualificados"; "Eu quero trabalhar no SUS".

Escolhi ministrar aulas na disciplina de Metodologia Científica, pois gosto da temática que envolve seu conteúdo. Os alunos frequentemente se queixavam que a disciplina era desinteressante e distante da Odontologia, já que era ministrada por docente não dentista. Não posso dizer que hoje os alunos passaram a gostar, pois seu conteúdo não é atrativo para a maioria, que gosta muito mais de práticas clínicas. Mas posso afirmar que meus colegas de disciplina e eu nos esforçamos a cada semestre para torná-la mais bem-sucedida no aproveitamento dos alunos. Nesta direção elaboramos um caderno didático para tornar mais acessível as concepções da metodologia científica aplicável à iniciação científica.

Fui docente da disciplina de Estágio em Clínica Odontológica Integrada I até 2010, em atividades práticas e teóricas. Pude mostrar aos alunos como realizar planos de tratamento com a visão integral do paciente, e a necessidade de manter a documentação legal - prontuário do paciente - de acordo com as normas do Conselho Federal de Odontologia.

Em 2011 aceitei supervisionar os estágios curriculares obrigatórios externos, inseridos como disciplinas de Estágios em Serviços de Saúde Pública I e II. Estas disciplinas são ofertadas no $9^{\circ}$ e $10^{\circ}$ semestres. Tem como característica a inserção do aluno em serviços de saúde do SUS, mas ainda não estavam adequadamente organizadas junto à Secretaria de Município da Saúde, principal instituição para o encaminhamento dos estagiários. Faço este trabalho até hoje e tem sido uma oportunidade de interferir mais, mesmo que minimamente, na formação em Saúde Coletiva. Embora não haja previsão de aulas teóricas, promovo em cada semestre os encontros teóricos, nos quais tenho a oportunidade de, nas discussões e compartilhamento de experiências entre os estagiários, inserir e apresentar conteúdos de Saúde Coletiva. Para os alunos começa a fazer sentido que nestes locais estará sua oportunidade de trabalho depois de formado, o que aumenta seu interesse por conhecimentos que não tiveram durante a graduação.

O processo de trabalho de supervisão dos estágios é bastante atribulado, pois exige atender os requisitos documentais e técnicos de cada instituição que recebe nossos alunos, confirmar os campos e preceptores de estágio a cada semestre, realizar visitas periódicas para o acompanhamento das atividades, e elaborar a documentação e orientação dos alunos com relação aos termos de compromisso de estágio, relatórios de atividades e avaliação do estagiário.

Durante este período pude ver com mais clareza o tamanho da responsabilidade do curso de Odontologia na formação de um profissional de saúde, e não apenas cirurgiãodentista. Constatei o despreparo dos cirurgiões-dentistas em exercer a profissão no SUS com competências e habilidades para a promoção, prevenção e recuperação em saúde de forma individual e coletiva, ou seja, apto para realizar a atenção integral dos indivíduos, famílias e comunidade, numa perspectiva multiprofissional e de acordo com as 
políticas públicas do setor. Esta lacuna na formação leva a que os cirurgiões-dentistas apenas observem que o sistema é ruim e se sintam descompromissados com as mudanças para torná-lo melhor. E como a formação é predominantemente especialista e realizada dentro dos muros da universidade, ou seja, distante da realidade, aumenta a frustração e a descrença de que pode ser diferente e melhor.

Ao analisar os relatórios dos estagiários em serviços do SUS elaboro, anualmente, um relatório geral e entrego ao Núcleo de Educação Permanente da Secretaria de Município da Saúde, como forma de retornar aos serviços o aproveitamento que os estagiários alcançaram, bem como sugerir mudanças estruturais e de processo de trabalho, com base nos relatórios individuais. E invariavelmente os estagiários, em sua maioria, valorizam este momento da sua formação pela oportunidade de conhecer os serviços e aprender com os preceptores. Meu papel é problematizar cada situação vivenciada por eles de forma a provocar uma reflexão crítica da sua vivência e para que pactuem consigo próprios novas práticas e atitudes que reflitam um profissional comprometido socialmente, ético e resolutivo no atendimento das necessidades da população.

Assim, em 2014, quando o Departamento de Sociologia e Política, do Centro de Ciências Sociais e Humanas sinalizou com a impossibilidade de continuar cedendo um professor para ministrar aulas na disciplina complementar de graduação denominada de Introdução às Ciências Sociais, aceitei esta função com muita satisfação. Era uma oportunidade excelente para melhorar e aumentar conteúdos de Saúde Coletiva. E está sendo um dos espaços mais gratificantes para a problematização do saber e fazer em saúde. Seu conteúdo abrange determinantes sociais de saúde, relações profissionalusuário, trabalho em equipe, ética, preconceito e discriminação, educação em saúde; mídia e saúde; participação da população na saúde; políticas públicas, entre outros. A metodologia ativa é a estratégia de escolha para o aprendizado nesta área.

\section{No PET Odontologia}

$\mathrm{Na}$ graduação tive a ocasião de diversificar minha experiência docente com o Programa de Educação Tutorial - PET - do Ministério de Educação.

O grupo PET Odontologia da UFSM foi criado em 2006, por iniciativa da profa. Katia Braun. Como a seleção seria na área temática de Políticas Públicas de Saúde, participei na elaboração do projeto e permaneci no programa como cotutora até 2011. Foram anos intensos, pois éramos desafiadas a desenvolver capacidade criadora a cada semestre, na proposição de atividades de ensino, pesquisa e extensão. Impossível indicar todas as atividades que vivenciamos, pois nem tudo pode ser registrado em papel; fica registrado na mente de cada um. Mas muitas podem ser constatadas nas produções técnicas e científicas registradas em nossos currículos.

Acredito que a proposta deste programa, de proporcionar aos alunos experiências não presentes em estruturas curriculares convencionais, visando à complementação de sua formação, atingiu seus objetivos, pois era muito visível a diferença entre alunos petianos e não petianos no curso. Foi neste período que implantamos uma clínica de 
saúde bucal voltada a catadores de resíduos sólidos e a idosos, e mais tarde à população quilombola, por meio de projetos de extensão. Utilizando uma clínica odontológica ociosa nas sextas feiras à tarde, construímos um espaço de aprendizado e convivência com alunos de todos os semestres letivos, e alguns professores voluntários.

Com a liberdade de trabalho que tínhamos, pudemos pôr em prática várias ações pedagógicas: elaboração de prontuário; planos de tratamento integrados; práticas coletivas de educação em saúde, intra e extramuros; espaços de discussão científica; participação em eventos, tanto científicos quanto sociais; deslocamentos até a região de um quilombo; e muito mais.

Estar naquele espaço, com aqueles alunos, depois de uma semana convencional de trabalho, era como estar em outra dimensão. Um sentimento de preenchimento, de missão cumprida. Mesmo assim, apesar de trabalhar em Saúde Coletiva, ainda era frustrante não desenvolver o aprendizado dos alunos no SUS. Então surgiu o PET Saúde, uma oportunidade de trabalho multiprofissional e totalmente vinculado ao serviço público.

\section{No PET Saúde}

Este programa tinha como finalidade articular as instituições de ensino superior e os serviços públicos para potencializar a formação de profissionais de saúde, produzir conhecimentos e buscar em conjunto as respostas às necessidades da população brasileira. Era uma reação do Ministério da Saúde ao pouco impacto que as diretrizes curriculares nacionais estavam causando na mudança do modelo de formação integrado ao sistema de saúde, como se esperava quando foram lançadas em 2002.

Embora no Centro de Ciências da Saúde houvesse um grupo multiprofissional de professores que vinha trabalhando no Programa Nacional de Reorientação da Formação Profissional em Saúde - Pró-Saúde - desde 2009, foi em 2011 que passei a integrar a equipe. O primeiro projeto em que participei estava vinculado ao Pró-Saúde e PETSaúde, edital n. 24/2011. A temática era sobre regiões de saúde e as redes de atenção à saúde. Participei do grupo da atenção primária em saúde como tutora voluntária, no projeto Redes de atenção à saúde na região centro-oeste do Rio Grande do Sul. O grupo era composto de estudantes oriundos de oito cursos da área da saúde, profissionais dos serviços de gestão e atenção básica do município, e docentes. Nosso foco era a Atenção Básica no município e na região centro.

O segundo projeto selecionado foi em 2013 na área temática Redes de Atenção à Saúde, edital n. 14/2013, e participei como tutora efetiva do grupo que trabalharia com ênfase em análise situacional da saúde e ampliação da capacidade de vigilância às emergências de saúde pública e desastre na cidade de Santa Maria: PET Saúde/Vigilância em Saúde. O grupo era composto de professores tutores, preceptores do setor de Vigilância em Saúde e da Secretaria de Município da Saúde de Santa Maria e estudantes dos oito cursos do Centro de Ciências da Saúde e mais Serviço Social, Medicina Veterinária e Educação Física. Nosso projeto inicial foi organizado em dois subprojetos: Análise situacional da saúde e Ampliação da capacidade de vigilância 
às emergências de saúde pública e desastre na cidade de Santa Maria. O segundo possuía uma necessidade específica em função do desastre por incêndio ocorrido numa casa noturna na cidade em 2013, em que morreram 242 pessoas, em sua maioria jovens e estudantes universitários.

Fui tutora efetiva de um grupo de seis estudantes e coordenadora de três projetos de pesquisa focados no tema Planejamento em Saúde. Coordenei também a elaboração de cartilhas sobre planejamento em saúde. Além das pesquisas, os estudantes participavam de vivências em serviços de saúde - no setor da Vigilância em Saúde e na rede de Atenção Básica do município -, realizavam seminários e participavam de eventos científicos, além elaborar material de divulgação das temáticas em que estavam envolvidos.

Praticamente todas as atividades do PET Saúde eram executadas em horário noturno, pois não havia possibilidade de reunir tantas pessoas, oriundas de tantos lugares e cursos diferentes, durante o dia. Significava uma carga extensa e intensa de trabalho manual e intelectual. Mas como descrever esta experiência de forma completa, já que quantidades não dão conta disso? Por que estávamos, os professores principalmente, tão engajados nas tarefas que nos propúnhamos a fazer?

Começo ressaltando o mérito deste programa: o de provocar a reunião de docentes em torno de uma causa comum: a formação do aluno da área da saúde inserida no SUS. Onde e quando teríamos uma oportunidade de realizar trabalho em equipe multiprofissional, interdisciplinar e transdisciplinar como tivemos no PET Saúde? Talvez porque todos os envolvidos já atuavam multiprofissionalmente na residência multiprofissional? Acredito que não.

A configuração foi diferente no PET: houve mais dinamismo, mais criatividade, mais independência, mais realidade. É assim que consigo descrever minha experiência: o crescimento como profissional de saúde e muito mais como docente; a certeza de que não estava errada ao querer mudar as concepções equivocadas sobre a Saúde Coletiva e o SUS no meu curso; o aumento do conhecimento técnico e científico que nenhum curso formal ou estudo teórico conseguiria proporcionar com tanta efetividade. Neste ponto, aposto com firmeza que a maioria dos estudantes envolvidos tiveram uma formação bastante diferenciada de quem não participou deste Programa.

Mas ressalto uma situação importante: a convivência com pessoas de diferentes concepções de vida e de trabalho. Foi fácil e tranquilo? Claro que não! Exatamente por isso que foi tão importante, e diante disso pude analisar muitas atitudes que tomei e reafirmar concepções e valores que orientam minha vida.

\section{Na residência multiprofissional}

Minha inserção no Programa de Residência Multiprofissional Integrada em Sistema Público de Saúde aconteceu em 2009, na área de concentração em Atenção Básica/Estratégia de Saúde da Família, por iniciativa de um ex-aluno do curso de Odontologia e então o único residente desta profissão, que solicitou minha participação como preceptora de núcleo. Embora eu não exercesse funções nos serviços de atenção básica, este residente buscava aperfeiçoar sua vivência nos serviços com um espaço de discussão e aprendizado teórico no Seminário de Núcleo instituído no Programa. 
O espaço da Odontologia cresceu no Programa e, em 2010, foram criadas vagas na área de concentração em Gestão e Atenção Hospitalar com mais três residentes nos setores de Hemato-Oncologia e Crônico-Degenerativo. Passei a ser a Tutora de Núcleo no Programa com o desafio de ampliar meus conhecimentos para a Odontologia Hospitalar.

Em 2012 assumi, junto com um colega da Medicina Veterinária, a disciplina de Epidemiologia e Vigilância em Saúde. Nesta época, as atividades docentes na Residência não eram contadas como encargos didáticos e as aulas teóricas eram noturnas, mas a oportunidade de inserção num espaço multiprofissional de saúde compensava qualquer necessidade de papel. Ainda mais para mim, pois era onde encontrava, conversava, trocava, aprendia e vivia Saúde Coletiva.

Com o acúmulo de atividades que possuía, já que era a única docente com formação em Saúde Coletiva no curso e, portanto, solicitada e indicada para várias frentes de trabalho nesta área, em 2013 renunciei à tutoria de Núcleo no ambiente hospitalar e concentrei as atividades na atenção básica.

Em 2014 houve a opção de as residentes da Odontologia realizarem carga horária complementar na 4 ${ }^{\text {a }}$ Coordenadoria Regional de Saúde, no setor de saúde bucal, com a preceptoria de um cirurgião-dentista. Esta experiência extremamente positiva, tanto para as residentes quanto para o profissional, levantou a necessidade de abrir vaga para a Odontologia na área de Concentração em Vigilância em Saúde, em 2015, situação que gerou uma integração ainda maior entre a minha disciplina e os serviços de saúde do SUS.

Como trabalhei na área temática de Planejamento em Saúde no Programa de Educação pelo Trabalho em Saúde, PET Saúde, e aprofundei conhecimentos sobre os instrumentos de gestão no SUS, colaboro com a coordenadora de Saúde Bucal do município na elaboração do Plano Municipal de Saúde Bucal, e o coordenador regional de Saúde Bucal, na planificação da atenção primária à saúde.

Acredito firmemente na importância da Residência Multiprofissional como espaço formador por sua integração aos serviços. Acompanho a transformação que provoca nos profissionais de saúde, cuja formação foi/é muito incipiente em Saúde Coletiva. Tornamse, na quase totalidade dos casos, profissionais com conhecimentos ampliados, críticos, reflexivos e com habilidades e competências importantes para realizar as mudanças esperadas no sistema de saúde.

\section{Na pós-graduação stricto sensu}

Minha passagem pelo Programa de Pós-Graduação em Ciências Odontológicas foi de 2008 a 2013. Novamente foi desafiador e extremamente bem-sucedido do ponto de vista formação intelectual.

Orientei quatro mestrandas, embora apenas uma delas tenha publicado seu trabalho de dissertação. Minha opção de pesquisa sempre foi orientada para as questões de formação e voltadas sobretudo para a Saúde Coletiva e SUS, além de preferir o método qualitativo de investigação. Seriam estas as comprovações para ser denominada 'improdutiva' na pós-graduação stricto sensu pela Capes? 
Fazer pesquisa no SUS pode ser publicável internacionalmente, requisito para se manter num programa de pós-graduação, desde que exista um ' $n$ ' significativo. Não era ou é minha primeira escolha. Eu prefiro, ainda, investigar em profundidade as subjetividades oriundas dos sujeitos envolvidos. E, com os resultados obtidos, interferir em curto e médio prazo para a solução do problema. O que é uma pesquisa senão a busca de solução para um determinado problema? Em se tratando de pessoas, como não apreender os significados de suas atitudes, crenças e valores que orientam sua vida na sociedade, para que se possa trabalhar com as mudanças que almejamos para uma vida melhor? Não significa descartar a estatística, mas fazer com que algumas estatísticas sangrem. Ou suem. Ou falem.

No início do programa não havia corpo docente suficiente para assumir todos os encargos que surgiram. Ofereci-me para assumir a disciplina de Metodologia do Ensino Superior. Meu interesse nesta área de conhecimento vinha de longe, da pós-graduação, mas também das minhas inquietações quando ao meu desempenho como professora. Pensei que no mestrado e no doutorado eu seria capacitada para esta função, mas eu e tantos outros mestres e doutores deste país não temos esta formação concretizada nos cursos de pós-graduação. Porque o foco é pesquisa, não a formação de educadores.

Diante disto estudei muito - de Sócrates a Paulo Freire, Ruben Alves e Edgar Morin, entre outros - e construí uma disciplina que foi ao encontro dos anseios dos mestrandos do programa. Compartilhei as experiências da graduação e as concepções pedagógicas e estratégias de aprendizagem mais atualizadas que a literatura indicava: problem based learning, metodologia da problematização, aula expositiva dialogada, seminários, trabalho em grupo, avaliação da aprendizagem como ato pedagógico, entre outras. $O$ reconhecimento dos mestrandos como a melhor disciplina do programa, na época, certamente foi um exagero, mas extremamente motivador para mim.

Foi a partir dos estudos e práticas que desenvolvi nesta atividade didática que passei a adotar, regularmente, um processo de avaliação de disciplina pelos alunos, a cada final de semestre, tanto na graduação quanto na pós-graduação. Isto tem qualificado cada vez mais minha prática docente.

Também fui responsável pela disciplina de Seminários de Promoção de Saúde. Embora fosse optativa um bom número de mestrandos a cursou e, particularmente, aproveitei a oportunidade para resgatar e consolidar conceitos de Saúde Coletiva. Foi impressionante constatar que a maioria confundia conceitualmente as expressões promoção de saúde com prevenção em saúde. Organizei a disciplina com metodologias ativas de aprendizagem. Ou seja, ali os alunos podiam exercitar os conceitos e pressupostos abordados na disciplina de Metodologia do Ensino Superior.

Poderia ter continuado como professora colaboradora no Programa de PósGraduação, depois que perdi o direito de orientar dissertações, mas meu interesse maior continuava na Saúde Coletiva. As atividades da Residência Multiprofissional e do PET Saúde eram intensas na época, e estando sozinha para atender as demandas da área, resolvi abrir mão destes encargos didáticos, não sem uma ponta de consternação.

\section{Nos espaços intra e extramuros}

Uma parceria entre o Projeto Esperança/Cooesperança, a Secretaria de Cultura e a Secretaria de Proteção Ambiental de Santa Maria originou o projeto Catando cidadania,

\begin{tabular}{|l|l|l|l|l|l|}
\hline Regae: Rev. Gest. Aval. Educ. & Santa Maria & v. 10 & n. especial & e66663, p. 1-18 & 2021
\end{tabular}


como o objetivo de inclusão social e cultural de catadores de resíduos sólidos da cidade. As atividades do grupo incluíam coral, teatro, bloco de carnaval, aulas de línguas estrangeiras e produção de artesanato. Foi levantada a necessidade, pelo próprio grupo, de incluir a melhora das condições de saúde bucal como elemento essencial para o resgate da cidadania que buscavam como indivíduos, famílias e coletividade. Fui convidada, em 2005, para uma reunião na Secretaria de Município da Saúde, onde conheci os membros do projeto e seus idealizadores, e soube da demanda dos catadores. Foi assim que surgiu o projeto acadêmico Catando cidadania com saúde bucal. Tínhamos uma clínica odontológica disponível para o atendimento das necessidades bucais e realizamos várias intervenções de educação em saúde, desafiadoras para alunos e professores envolvidos, pois tínhamos que buscar formas alternativas de abordagem, considerando as várias carências e vulnerabilidades desta população. Para os alunos foi um marco importante, pois dificilmente teriam uma oportunidade como esta, de conhecimento e responsabilidade social na sua formação.

Como resposta ao incentivo da colega da disciplina de Prótese Dentária Removível, elaborei em 2007 um projeto de ensino e extensão denominado Saúde bucal na atenção básica, para vivenciar a estrutura e o processo de trabalho de um cirurgião-dentista numa unidade básica de saúde.

O projeto foi uma possibilidade, como docente de Saúde Coletiva, de minimizar os efeitos da falta deste conhecimento na formação em Odontologia. No início convidei alguns alunos que se mostraram interessados, mas depois tive que realizar um processo seletivo, pois começou a haver um grande interesse dos acadêmicos. As atividades compreendiam desde atendimento clínico a usuários que foram priorizados em razão de condições de risco social, de saúde geral e de saúde bucal, com a parceria dos Agentes Comunitários de Saúde - ACS -, como intervenções educativas na comunidade. Os alunos realizavam visita domiciliar com as ACS. Casos mais complexos eram referenciados para o curso de Odontologia. Foi a primeira vez que os alunos atenderam uma paciente HIV positiva, que se declarou nessa condição, e que não tinha tido oportunidade de realizar tratamento odontológico por causa do preconceito. Neste local orientei 12 alunos, durante três semestres letivos e pude, além de mostrar o sistema a eles, aprender muito mais sobre ele. E confirmar, pelos depoimentos satisfatórios e encorajadores, que este era o caminho a ser seguido para uma formação adequada: em serviços.

Fui palestrante em conferências municipais de saúde por duas vezes, em Santo Ângelo e São Sepé, antes de atender ao convite para ir a Júlio de Castilhos em 2011. Nesta minha terceira palestra construí minha apresentação em torno do papel da comunicação e da informação em saúde e da importância de ser conselheiro de saúde. Salientei que os conselheiros devem estar bem-informados quando são solicitados a votar, aprovando ou reprovando um projeto ou demanda do município. Semanas depois, fui informada que um dos membros do Conselho Municipal da cidade, representante dos usuários, tinha solicitado esclarecimentos a respeito de uma demanda a ser votada, citando minha exposição na conferência.

Em 2014, em substituição aos Pólos de Educação Permanente em Saúde no Brasil, foram criadas instancias intersetoriais e interinstitucionais para a formulação, condução e desenvolvimento da Política de Educação Permanente em Saúde no SUS. Minha 
participação na Comissão de Integração Ensino Serviço - Cies -, da 4⿳亠丷厂 Coordenadoria Regional de Saúde iniciou como suplente da profa Taísa Ferreira, do curso de Terapia Ocupacional, representando a UFSM. Mesmo suplente frequentei regularmente todas as reuniões. Neste âmbito eram discutidas propostas e projetos originados nos 32 municípios das regiões de saúde Verdes Campos e Entre Rios. Pude colaborar na emissão de pareceres sobre os projetos enviados para avaliação e solicitação de recursos financeiros.

Muitas vezes nos deparamos com situações instigantes, como a de um aluno do $2^{\circ}$ semestre que veio conversar sobre assuntos de aula e comentou estranhar o fato de 0 curso de Odontologia não ter uma página eletrônica no site da universidade. Mais um pouco de conversa e já estávamos planejando o delineamento, com mais dois colegas de turma. Construído o projeto de extensão em julho de 2015 - Criação da página eletrônica do curso de Odontologia - e feita a capacitação como administradores com o Centro de Processamento de Dados da UFSM, a página entrou no sistema em janeiro de 2016. Abracei esta causa por motivos muito práticos: a necessidade de termos transparência no curso, a possibilidade de se constituir num canal de informação mais ágil para a comunidade acadêmica e a sociedade em geral, e finalmente a de valorizar nosso curso mostrando nossas atividades e propostas de formação em ensino, pesquisa e extensão.

A Residência Multiprofissional ampliou e consolidou minhas relações com a gestão do SUS de modo geral, mas principalmente com a Coordenação Municipal de Saúde Bucal de Santa Maria e a Coordenação Regional de Saúde Bucal da 4⿳亠丷 CRS. Em todas as oportunidades possíveis saliento que os serviços de saúde devem considerar que as universidades públicas têm compromisso com transformações sociais para melhorar as condições de vida da população, e isto não acontece somente no momento da formação. Nesse sentido, o vínculo criado permitiu que eu contribuísse na elaboração do Plano Municipal de Saúde Bucal, e pudesse participar das oficinas de Planificação da Atenção Primária em Saúde Bucal, cooperando com a elaboração de protocolos para a organização da demanda nos serviços e sugerindo a criação de diretrizes de trabalho que orientem os profissionais no cotidiano do serviço odontológico. Além disso, o fato de estar na supervisão dos estágios me permite um estreitamento das relações com todos os profissionais ditos 'da ponta', ampliando a capacidade de diálogo e estreitando relações de ensino-serviço.

Ao longo dos anos fui me envolvendo em várias ações e projetos que diziam respeito à minha área de conhecimento e interesse profissional. $\mathrm{E}$ em todas elas meu desempenho docente foi e está sendo aprimorado. As atividades que registro aqui tem importância pessoal e profissional, pois são resultados do meu envolvimento externo à UFSM, ou seja, a universidade indo ao encontro da sociedade. Estas experiências externas são fundamentais para que eu possa levar à sala de aula conteúdos e experiências reais, dando sentido ao conteúdo teórico científico que orienta a formação em Saúde Coletiva.

\section{Na produção intelectual}

A redação de artigos, técnicos e científicos, é um trabalho que gosto de fazer. Mas não o faço na medida do meu desejo. O trabalho minucioso, de inspiração e transpiração, demanda uma dedicação de tempo que não possuo na maior parte do semestre letivo. 
Mesmo assim, é possível orientar alunos interessados em pesquisa e assim, publicar. É o que aconteceu na maioria dos produtos intelectuais que escrevi, e as temáticas refletem fundamentalmente minhas escolhas didático-pedagógicas.

A pesquisa e a extensão são oportunidades de aprendizado ímpares para os alunos e um processo intrínseco à atividade docente. $O$ envolvimento gera, além disso, a possibilidade de divulgação de trabalhos em eventos, o que para eles constitui um aprendizado externo à sala de aula, mas não menos importante: estudo, preparo, sistematização e criatividade na montagem da apresentação; disciplina para seguir as orientações do evento; autoconfiança e autonomia na defesa de seu trabalho; ampliação das relações com seus pares, entre tantos outros.

Outro fator de caráter prático e pedagógico nas relações de pesquisa e extensão é que gosto de inserir alunos de semestres iniciais nos trabalhos, orientando-os com aspectos bem básicos do conhecimento e da investigação. Isto os deixa mais confiantes para desenvolver pesquisas mais complexas e até mesmo outras experiências durante a formação.

Em 2015, por iniciativa do meu colega de disciplina, formamos um grupo de pesquisa constituído de 14 alunos de diferentes semestres da graduação envolvidos com iniciação científica, com direito a uma logomarca de identificação e divulgação do grupo, denominado de Coletivo saúde. Uma situação muito inusitada e gratificante foi planejada por dois alunos: inscrever-se num Congresso Internacional de História e falar sobre o SUS. O trabalho foi aceito, apresentado e elogiado pela sua originalidade e iniciativa, surpreendendo os organizadores do evento.

Um produto intelectual muito importante, originado no PET Saúde, foi o das Cartilhas de planejamento e avaliação em saúde. Trata-se de três cartilhas com os temas pactuação de indicadores no planejamento em saúde; planejamento em saúde: instrumentos de gestão e territorialização em saúde. Foram produzidos para distribuição em serviços de saúde do SUS com o propósito de esclarecer e motivar usuários e trabalhadores de saúde sobre a importância de conhecer e participar da gestão da saúde no município. Além de conter informações e orientações básicas, fornece referências de documentos e textos facilmente acessíveis pela internet para complementar os temas abordados.

Considero a avaliação de artigos como consultora ad hoc como uma tarefa educativa formativa, pois a análise dos trabalhos permite exercitar minha competência científica e a capacidade crítica. Meu julgamento não pode prescindir de um conhecimento prévio sobre o assunto e de coerência na exposição dos fatores que elevam ou diminuem o valor científico do trabalho. O parecer deve vir acompanhado de argumentos que justificam claramente as correções ou mesmo a recomendação de não aceitar a publicação. Afinal, quem de nós não teve trabalhos recusados para publicação? Não gostaríamos de ter um julgamento transparente?

No que diz respeito às premiações de trabalhos, considero que o mérito é dos alunos. Embora os três trabalhos premiados estivessem sob minha responsabilidade e orientação, a apresentação e defesa é feita por eles. 


\section{Nas atividades de representação}

A experiência de integrar o Conselho de Ensino, Pesquisa e Extensão - Cepe - em 2008 foi muito interessante, pois significava estar numa das instâncias superiores da universidade onde as decisões eram tomadas em caráter praticamente definitivo, gerando repercussões diretas na comunidade acadêmica. Minha passagem foi curta, pois era representante dos professores adjuntos e logo em seguida obtive progressão funcional para associado, sendo desligada automaticamente desta função.

$\mathrm{Na}$ Comissão de Extensão do Centro de Ciências da Saúde, em 2011, quando fazíamos a avaliação dos projetos candidatos a recursos do Fundo de Incentivo à Extensão - Fiex -, observávamos que muitos projetos não contemplavam os requisitos de um projeto de extensão e outros eram claramente de pesquisa, mas requisitavam recursos do Fiex. Tive a oportunidade de colaborar diretamente na edição de um texto orientador para elaboração de projetos de extensão. Este texto está disponível na página eletrônica do Gabinete de Projetos do Centro de Ciências da Saúde: Roteiro para elaboração de ações de extensão.

No contexto da avaliação de projetos submetidos à Comissão de Integração EnsinoServiços - Cies -, na qual estava como representante suplente da UFSM, pude perceber as dificuldades dos proponentes em redigir adequadamente os textos, do ponto de vista metodológico. Foi então sugerida minha intervenção no Encontro de Educação Permanente, em 2015, para ministrar uma oficina de elaboração de projetos e escrita científica. Pude perceber que a dificuldade maior dos trabalhadores se devia ao pouco contato que mantinham com aspectos acadêmicos de produção de textos e trabalhos, uma vez que seu cotidiano nos serviços é concentrado em atividades práticas.

Comecei a fazer parte do Colegiado em 2010. Como as reuniões não são regulares e nunca houve uma em que todos os membros estivessem presentes, uma colega e eu nos dispusemos a revisar o regimento, buscando atualizá-lo para as normas institucionais vigentes e instituindo a figura do suplente, para garantir o comparecimento de todos os representantes. Ao fazer uma revisão das atas das reuniões percebi claramente a evolução do que é registrado: no início com a reprodução das discussões e opiniões de cada membro que se manifesta, para um registro formal de comunicações, aprovações ou reprovações de demandas, sem qualquer apontamento de pontos de vista ou de análise de mérito dos assuntos de pauta.

Durante o processo de revisão do Regimento do Colegiado e nas atividades do Núcleo Docente Estruturante - NDE - pude entender com mais clareza qual é seu papel administrativo e institucional. O Regimento Geral da UFSM estabelece as competências do colegiado, as quais constam no regimento do curso de Odontologia (UFSM, 2021). Dentre elas está: $V$ - propor a substituição ou qualificação de professores ou outras providências necessárias à melhoria do ensino ministrado. Em nenhum momento, durante as várias intervenções que fiz para manifestar a situação da disciplina de Odontologia em Saúde Coletiva, consegui sensibilizar o colegiado do curso para uma atitude nesta direção.

\section{No Núcleo Docente Estruturante}

Em 2013 surgiu a oportunidade de constituir o Núcleo Docente Estruturante - NDE do curso de Odontologia. Esta estrutura foi originalmente concebida, em 2007, para

\begin{tabular}{|l|l|l|l|l|l|}
\hline Regae: Rev. Gest. Aval. Educ. & Santa Maria & v. 10 & n. especial & e66663, p. 1-18 & 2021 \\
\hline
\end{tabular} 
normatizar a criação de cursos de Medicina e Direito. Em 2010 a Comissão Nacional de Avaliação da Educação Superior - Conaes - propôs a formalização destes núcleos em todos os cursos para conceber, acompanhar, consolidar e atualizar o projeto pedagógico dos cursos (Brasil, 2010). A afirmações que constam no parecer n. 04/2010 soaram como um chamado para mim:

Um bom curso de graduação tem alguns membros do seu corpo docente que ajudam a construir a identidade do mesmo [...] educação se faz com pessoas e [...] há, em todo grupo social, um processo de liderança que está além dos cargos instituídos [...]. Se a identidade de um curso depende dessas pessoas [...] é justo que se entenda e se incentive o reconhecimento delas, institucionalmente, para qualificar [...] um projeto pedagógico de curso. Com isso se pode evitar que os PPCs sejam uma peça meramente documental.

Finalmente materializa-se um espaço de discussão e avaliação do ensino. Aceitei o convite da então vice-coordenadora do curso, para organizar as atividades e, junto com mais três professores, iniciamos um processo de avaliação formal do currículo, junto a professores e alunos.

Com os resultados da avaliação e as análises do projeto pedagógico em vigor pudemos elaborar propostas de reformulação que foram compartilhadas regularmente com toda a comunidade acadêmica da Odontologia. Não é possível trabalhar em nome de um coletivo e para um coletivo se não são adotadas estratégias de informação, inclusão e comprometimento das pessoas implicadas diretamente. Uma destas formas é por meio da transparência das ações, uma das questões fundamentais que sempre ressaltei no NDE.

No ano de 2014 o curso recebeu a visita de uma comissão do Inep composta por três professores: uma brasileira, um chileno e uma argentina. Sua missão era a de avaliar o curso para a acreditação junto ao Mercosul. Transcrevo um recorte do que foi escrito no relatório que a comissão enviou à coordenação:

Durante a visita e entrevistas concluímos que o Projeto Pedagógico do curso de Odontologia descreve atender às Diretrizes Curriculares Nacionais, mas verificamos que a Odontologia em Saúde Coletiva precisa ser objeto de análise do Núcleo Docente Estruturante, que pudemos atestar que é uma instância que está preocupada com a integração das diversas disciplinas e dos conteúdos para a formação de um cirurgião dentista comprometido com as necessidades sociais e regionais. [...] Quanto aos aspectos éticos da prática odontológica, eles não constituem conteúdo das disciplinas de Odontologia em Saúde Coletiva I, II e III, havendo apenas uma aula na primeira disciplina. $\mathrm{Na}$ reunião com docentes, ao ser perguntado como era ministrado este conteúdo, foi- nos respondido que os docentes o passavam aos alunos durante suas aulas práticas. Verificamos que o grande problema está localizado na alocação das vagas docentes, pois só há no quadro uma docente com titulação em Odontologia em Saúde Coletiva, que brevemente completará o tempo de serviço para solicitar aposentadoria. O mesmo se passa com o conteúdo de Odontologia Legal, que não tem docente para ministrá-lo. Cremos, após análises e entrevistas, que esta questão demonstra que não há uma autoridade ou órgão colegiado, superior às chefias de departamento, que tenha uma visão global do curso, podendo deliberar com isenção sobre a 
alocação de vagas docentes. É necessário refletir sobre este ponto e avaliar o corpo docente global do curso para fundamentar a solicitação de vagas. (UFSM, 2014)

Estava aberta a possibilidade de desencadear, finalmente, uma mudança concreta na minha disciplina. E ela aconteceu. Mudei radicalmente a configuração e o conteúdo para atender as exigências legais e estruturais no projeto pedagógico, mas principalmente e finalmente, para colocar em prática nas aulas todo o conteúdo necessário para formar um cirurgião-dentista como profissional de saúde, não somente um profissional de dentes, gengiva e ossos. Em 2015 houve realização de concurso público para uma vaga na disciplina. $O$ docente aprovado não poderia estar mais preparado para assumir esta função: graduação em Odontologia pela Universidade Federal de Santa Maria; mestrado em Saúde Bucal Coletiva pela Universidade Federal do Rio Grande do Sul; Residência Multiprofissional Integrada em Saúde Coletiva pela Universidade Federal de Santa Maria; doutorado em Epidemiologia pela Universidade Federal do Rio Grande do Sul. O currículo reformulado entrou em vigor em março de 2017.

\section{Na participação em bancas e eventos acadêmicos}

A avaliação de pesquisas, principalmente daquelas que não envolvem diretamente nossa área de atuação é uma tarefa difícil, mas nem por isso deixa de ser importante, pois nos faz sair da zona de conforto de achar que somente nossa disciplina ou área de conhecimento é importante. Sem contar que aprendemos, constantemente.

Minha participação nos eventos acadêmicos tem relação direta com minha opção de pesquisa da tese de doutorado: a formação do profissional de saúde para o trabalho no SUS. E não poderia ser diferente quando discutíamos a influência dos projetos PET na formação dos profissionais de saúde.

\section{No papel de educadora}

Como realizar uma análise de trajetória docente e não dedicar um espaço para o papel dos professores como educadores?

Minhas reflexões partem dos significados de educadora. A experiência como docente da disciplina de Metodologia do Ensino Superior certamente contribuiu para eu encontrar algumas respostas às questões que sempre me inquietaram, mas se não olharmos em volta e buscarmos compreender como as coisas funcionam, nunca saberemos o suficiente. Os alunos são a razão do nosso existir e fazer.

Estar com a turma do primeiro semestre do curso é um momento privilegiado. Todos estão ávidos por novas experiências e conhecimentos. Mas também se percebe certa ingenuidade em relação a profissão que escolheram. Cabe a mim informar: nem tudo será como imaginam quando estiverem prontos para ingressar no mercado de trabalho. Mas muito interessante é ministrar aulas em vários semestres do curso, acompanhando a transformação dos alunos, suas expectativas, seu amadurecimento, as escolhas.

Muito mais do que transmissora de conteúdos formatados em slides, sinto-me plena no papel de facilitadora do aprendizado. Embora muitos alunos tenham a concepção de que o conhecimento deva ser oferecido em pacotes - conteúdos, disciplinas -, as oportunidades de rodas de conversa, problematizações, seminários, realização de 
pesquisas, participação em projetos, entre outras modalidades, provocam no início algum desconforto, para muitos, pois eles têm que sair da passividade para se tornarem sujeitos ativos do seu aprendizado. Uma abordagem educativa por meio das tecnologias de informação - Moodle - tem sido um aliado forte, mas ainda necessita mais adesão por parte dos alunos, não acostumados a construir e organizar seu apreender e aprender. Mas depois que lidam com estes desafios, se tornam mais dinâmicos, abertos a exercitar um espírito mais crítico e reflexivo, que é o que desejamos de um aluno e de um profissional.

Nosso papel de educadores só se aprimora se somos desafiados pelos alunos. Quanto mais eles nos desafiarem, mais aprendemos. E como seres humanos, professores ou não, o aprendizado nunca acaba.

Busco também ser uma educadora no sentido de ter transparência nos atos e nas falas, mas principalmente usar minhas atitudes e comportamento como exemplo. Em tempos líquidos e de pós verdade.

Minha relação com os alunos sempre foi pautada pela necessidade de ser uma pessoa aberta a uma boa conversa. Boa conversa no sentido de eles se sentirem acolhidos para falar de suas vidas e de seus problemas, também.

A sala 109, a sala da disciplina na antiga Reitoria, tem sido assim: um espaço de convivência e uma boa conversa. Lágrimas, mas muitos risos, passam por lá.

\section{Considerações finais}

A narrativa deste memorial reflete minha experiência docente, mas não caracteriza um episódio único. É uma série. A primeira temporada terminou em 2016. A segunda temporada começou em 2017.

A opção por expor claramente esta trajetória, por meio de reflexões pessoais sobre estruturas e processos na universidade não tem nenhuma conotação de acusação ou de lamento. Pelo contrário, expõe a realidade. Que é conhecida por todos aqueles que destinam algum tempo para refletir sobre a universidade pública e sua estrutura. $E$ foi nesta realidade que transitei até hoje, $\mathrm{E}$ onde vou transitar ainda, por algum tempo, pois quero um recomeçar.

Este memorial deveria relatar apenas as conquistas e não as derrotas? Mas quem passa por uma vida sem derrotas? Ninguém!

Sou feliz como professora, realizada, e com a consciência de que batalhei pelos espaços que ocupei e ocupo. Não usei as melhores armas, provavelmente aquelas da negociação, as armas políticas. Preferi as técnicas. Não foram suficientes. Mas não me arrependo, pois fui coerente com meus princípios e valores, do começo até onde eu for, ao fim.

\section{Referências}

BRASIL. Resolução CNE/CES n. 3, de 19 de fevereiro de 2002: institui diretrizes curriculares nacionais do curso de graduação em Odontologia. Brasília: CNE/CES. Disponível em: http://portal.mec.gov.br/cne/arquivos/pdf/CES032002.pdf. Acesso em: 6 jul. 2021.

BRASIL. Parecer n. 04/2010: normatiza o núcleo docente estruturante e dá outras providências.

Disponível 
http://portal.mec.gov.br/index.php?option=com docman\&view=download\&alias=6885-

resoluca01-2010- conae\&category slug=outubro-2010-pdf\&ltemid=30192. Acesso em: 6 jul. 2021.

BRASIL. Lei n. 8.080, de 19 de setembro de 1990: dispõe sobre as condições para a promoção, proteção e recuperação da saúde, a organização e o funcionamento dos serviços correspondentes e dá outras providências. Disponível em: http://www.planalto.gov.br/ccivil 03/leis/l8080.htm. Acesso em: 6 jul. 2021.

BRASIL. Parecer n. 370/82, aprovado em 9 de julho de 1982: proposta do novo currículo mínimo para o curso de graduação em Odontologia. Brasília: MEC, 1982, p. 46-54.

UFSM. Relatório Inep 2014. Disponível na Coordenação do curso de Odontologia.

UFSM. Regimento geral da UFSM. Santa Maria: UFSM, 2019. Disponível em: https://www.ufsm.br/pro-reitorias/proplan/regimento-geral-da-ufsm-com-alteracoescompiladas-pela-resolucao-n-016-2019. Acesso em: 6 jul. 2021.

Beatriz Unfer é professora na Universidade Federal de Santa Maria.

Orcid: https://orcid.org/0000-0002-8598-0671.

Endereço: Avenida Roraima, 1000 - prédio 26F - sala 2181 - 97105-900 - Santa Maria - RS - Brasil.

E-mail: beatriz.unfer@ufsm.br.

Critérios de autoria: Beatriz Unfer concebeu o texto na sua integralidade.

Recebido em 9 de julho de 2021.

Aceito em 12 de outubro de 2021.

cc) (i) (8) $\odot$ 